\title{
O ENSINO DE GEOGRAFIA NO BRASIL: DISCUSSÕES SOBRE A PRÁTICA REFLEXIVA NA SALA DE AULA
}

\author{
Ronaldo Costa Barbosa, Carmen Lúcia Dias
}

Universidade do Oeste Paulista - UNOESTE, Programa de Pós Graduação em Educação, Presidente Prudente, SP. Email: ronaldocostabarbosa@yahoo.com.br

\section{RESUMO}

Este artigo tem como objetivo discutir a trajetória do ensino de geografia nas políticas curriculares brasileiras a partir da década de 1960, buscando apresentar considerações sobre as mudanças no contexto da sala de aula tendo como base o conceito de professor reflexivo, a partir das reflexões de Pimenta (2006). Para atingir tal objetivo, utilizamos como metodologia a pesquisa bibliográfica, analisando as proposições de autores que se dedicaram a refletir sobre o ensino de geografia e sobre o papel do professor reflexivo na construção de sua prática. Com a contribuição das reflexões desses autores podemos observar que as propostas curriculares se concretizaram de forma verticalizada, sem diálogo com os professores que compõem parte essencial do processo educativo. Em um cenário de incertezas, este conceito ganhou espaço na educação brasileira, levando os profissionais da educação a repensar sua prática para atingir o aprendizado de seus alunos.

Palavras-chave: Ensino de Geografia. Professor Reflexivo. Ação Docente.

\section{GEOGRAPHY TEACHING IN BRAZIL: DISCUSSIONS ON REFLEXTIVE PRACTICE IN THE CLASSROOM}

\begin{abstract}
This article aims at discussing the history of geography on Brazilian curriculum policies since the decade of 1960, focusing on presenting important points on the changes in the classroom context having as basis the concept of a reflexive teacher, from Pimenta's reflexions (2006). In order to reach such objective, the methodology used was the one of bibliographic research, analyzing the author propositions who have been dedicated to reflect on geography teaching and on the role of the reflexive teacher in the process of build his/her practices. With the contribution of these authors' reflections, it is possible to note that the curricular proposals are carried out vertically, with no dialogue with the teachers who are an essential part of the educating program. In a context of uncertainties, this concept has grown in Brazilian education, leading the education professionals to reflect on their practices to reach the learning results in their students.
\end{abstract}

Keywords: Geography Teaching. Reflexive Teacher. Teaching Action. 


\section{INTRODUÇÃO}

A ciência geografia passou por mudanças profundas a partir da década de 1960. A Geografia Tradicional, apoiada em fortes influências positivas, passou a ser questionada com a emergência do movimento de renovação da geografia, apoiado principalmente pela Geografia Crítica. Nas décadas seguintes, novas proposições sobre o objeto de estudo passaram a ser discutidas, e tais mudanças se refletiram nas concepções curriculares para a disciplina escolar, bem como na ação do docente na formação das novas gerações.

Com as reformas curriculares das décadas de 1980 e 1990, novas demandas surgiram em relação às práticas pedagógicas, que se traduziram em mudanças significativas na estrutura das escolas bem como na relação entre o professor e o aluno.

Nesse cenário, o papel do docente também foi alterado, com o surgimento de novas demandas oriundas da crescente universalização da oferta de ensino na Educação Básica. $O$ acesso de todos a escola criou novas necessidades que, para serem atendidas, exigiram "novos" professores.

O conceito defendido pelo professor Donald Schön de professor reflexivo ganhou espaço na educação brasileira. Conforme nos afirma Pimenta (2006), Schön

[...] propõe que a formação dos profissionais não mais se dê nos moldes de um currículo normativo que primeiro apresenta a ciência, depois a sua aplicação e por último estágio a sua aplicação pelos alunos dos conhecimentos técnico-profissionais. O profissional assim formado [...] não consegue dar resposta às situações que emergem no dia-a-dia profissional, porque estas ultrapassam os conhecimentos elaborados pela ciência e as respostas técnicas que esta poderia oferecer ainda não estão formuladas. (p. 19).

Compreende-se que a "nova" escola requer profissionais que possuam capacidade de ir além da mera reprodução técnica dos conceitos e conteúdos desenvolvidos durante sua formação, mas que também seja criativo e dominem a capacidade de criar soluções para as novas demandas que emergem no cotidiano da sala de aula. Assim,

[...] Schön propõe uma formação profissional baseada numa epistemologia da prática, ou seja, na valorização da prática profissional como momento de construção de conhecimento, através da reflexão, análise e problematização desta, e o reconhecimento do conhecimento tácito, presente nas soluções que os profissionais encontram em ato. (PIMENTA, 2006, p.19)

Nesse contexto, este artigo tem como objetivo discutir a trajetória do ensino de geografia nas políticas curriculares brasileiras a partir da década de 1960, buscando apresentar considerações sobre as mudanças pelas quais a ciência geográfica passou nas últimas cinco décadas e como as mesmas se traduziram no contexto da sala de aula tendo como base o conceito de professor reflexivo, a partir das reflexões de Pimenta (2006).

\section{METODOLOGIA}

Esta pesquisa bibliográfica (SALVADOR, 1991), teve como aporte teórico a revisão de literatura especializada publicada sobre o tema, com autores que propõem uma discussão do conceito de professor reflexivo (PIMENTA, 2006), bem como publicações sobre a trajetória do ensino de geografia no Brasil (GEBRAN, 2003; PINHEIRO, 2003). 


\section{DISCUSSÃO}

Ao analisar as proposições curriculares para o ensino de Geografia, temos de considerar as mudanças que a própria ciência geográfica tem passado ao longo do tempo. As discussões acerca de seu objeto de estudo bem como dos fundamentos teórico-metodológicos têm influência direta no cotidiano das salas de aula. Para tanto, é necessária uma reflexão sobre o histórico do ensino de Geografia nas escolas brasileiras, especialmente nas últimas décadas do século XX e início do século XXI.

As décadas de 1960 e 1970 vivenciaram o desenvolvimento de um ensino tecnicista, pautado pelo positivismo clássico da Geografia Tradicional. As mudanças introduzidas pela Lei 5692/71 davam à Geografia uma visão tecnicista, economicista e sistêmica, e, a despeito da ampliação do acesso à escola, estas reformas limitaram o acesso ao saber, por considerar que a Geografia não contribuía para a formação de uma sociedade obediente e massificadora (GEBRAN, 2003).

A década de 1980 representa a introdução de uma nova concepção, a Geografia Crítica, presente nos debates e na proposição de novas Propostas Curriculares. Em São Paulo, as discussões ficaram a cargo da Coordenadoria de Estudos e Normas Pedagógicas (CENP), que produziu um esboço posteriormente submetido à discussão com professores do Ensino Fundamental e Médio e professores universitários (PINHEIRO, 2003). É importante ressaltar que

Os encontros de professores da rede estadual com as universidades, com objetivo de formulação de diferentes propostas de ensino para as diferentes áreas do conhecimento, constituíram espaço primordial para a redimensão da ação pedagógica, que culminaram com a elaboração de Propostas Curriculares. No que se refere à disciplina Geografia, tais propostas, (...) apresentaram novos caminhos no sentido de viabilizar possibilidades de uma ação pedagógica redimensionada. (GEBRAN, 2003, p. 84).

Verifica-se que a abertura do diálogo entre os docentes da rede e as Universidades foi de fundamental importância para a construção de uma proposta curricular que atendesse aos anseios sociais, visando à formação cidadã dos alunos, objetivando aproximar a escola da realidade na qual estava inserida e viabilizando meios para a intervenção.

Refletindo a realidade da "Nova Ordem Mundial" e as políticas neoliberais efetivadas pela ação do Banco Mundial (BM), a década de 1990 foi marcada pela promulgação da Lei 9394/96 Lei de Diretrizes e Bases da Educação Nacional e dos Parâmetros Curriculares Nacionais (PCNs) para o Ensino Fundamental e Médio, introduzindo uma educação pautada pela eficiência e produtividade (PINHEIRO, 2003). Embora os PCNs reforçassem um discurso favorável à descentralização, na prática se consolidaram como um instrumento de centralização política, uma vez que idealizaram uma visão de professor, escola e aluno que não condiz com a situação brasileira ao desconsiderar o diálogo e a realidade do cotidiano escolar (GEBRAN, 2003). Sobre este assunto, Pimenta (2006), ao refletir sobre as ideias de Schön, ressalta a importância de as reformas curriculares darem voz aos educadores, ao invés de apenas impor caminhos a serem seguidos na sala de aula. Dessa forma, nos afirma que:

[...] também se indagava sobre o papel dos professores nas reformas curriculares. Seriam estes meros executores de decisões tomadas em outras instâncias? Pesquisas já vinham apontando a importância da participação destes e da incorporação de suas ideias, seus conhecimentos, suas representações, na elaboração das propostas implantadas. O reconhecimento destes como sujeitos participantes das propostas se constituía em requisito imprescindível no sucesso da implantação de 
mudanças. E o conceito de professor reflexivo apontava possibilidades nessa direção. (PIMENTA, 2006, p. 21)

Contudo, conforme nos atestam Pinheiro (2003), Gebran (2003) e Oliveira (2012), as inovações teórico-metodológicas trazidas pelas propostas curriculares das décadas de 1980 e 1990 não se efetivaram no cotidiano escolar, dificultadas principalmente pela ausência de diálogo entre as partes envolvidas. O resultado de avaliações externas como o Exame Nacional do Ensino Médio (ENEM) e o Sistema de Avaliação do Rendimento Escolar do Estado de São Paulo (SARESP), já em suas primeiras edições, indicavam o baixo desempenho dos alunos concluintes da Educação Básica nas escolas estaduais de São Paulo.

Nesse contexto, de necessidade de novas "soluções" para as dificuldades enfrentadas pelos professores em sua prática cotidiana, aumenta a importância da pesquisa em educação como alternativa para a busca de tais "soluções". Dessa forma,

A informação sobre a existência desses movimentos em diferentes países chegou sistematicamente até nós e tomou fôlego mediante a publicação da coletânea organizada por Antonio Nóvoa (1992), sob o título de Os professores e a sua formação. Nela encontram-se traduzidos em língua portuguesa artigos de vários autores que discutem a formação de professores tendo como premissa a necessidade de revisão da pesquisa educacional para dar conta das demandas do ensino. (FAGUNDES, 2016, p. 283).

Porém, o conceito de professor reflexivo precisa ser ampliado e analisado a luz da realidade educacional brasileira. Conforme Pimenta (2006, p. 22-25), devemos considerar os seguintes aspectos em relação ao conceito:

1-) A supervalorização do professor enquanto indivíduo autônomo em sua prática pode levar a um "praticismo" exagerado e criar a noção de que basta apenas a prática para a construção do saber docente.

2-) Apenas a reflexão sobre a prática docente não basta, uma vez que o docente precisa ser capaz de tomar posições efetivas e concretas para reduzir os problemas oriundos de sua prática.

3-) Ao conceder aos professores a função de mediação pública e facilitadores do diálogo, Schön se utiliza de um enfoque reducionista, uma vez que desconsidera aspectos institucionais que influenciam na prática docente e, muitas vezes, inviabilizam a ação pedagógica reflexiva.

Ainda segundo Pimenta (2006), o que se verificou no Brasil foi um "treinamento para que o professor se torne reflexivo" (p. 23), o que massifica o conceito e dificulta o engajamento dos professores com as práticas críticas, tornando a aplicação do conceito uma ação técnica. É necessária uma conciliação entre a teoria e a prática na formação docente, o que, geralmente, ocorre apenas ao final da formação dos professores durante o Estágio Supervisionado. Dessa forma,

[...] quanto à abordagem da prática reflexiva, torna-se necessário estabelecer os limites políticos, institucionais e teórico-metodológicos relacionados a esta, para que não se incorra numa individualização do professor, advinda da desconsideração do contexto em que ele está inserido. A transformação da prática dos professores deve se dar, pois, numa perspectiva crítica. Assim, deve ser adotada uma postura cautelosa na abordagem da prática reflexiva, evitando a ênfase no professor que não venha a operar, estranhamente, a separação da sua prática do contexto organizacional no qual ocorre. Fica, portanto, evidenciada a necessidade da 
realização de uma articulação, no âmbito das investigações sobre a prática reflexiva, entre práticas cotidianas e contextos mais amplos, considerando o ensino como prática social concreta. (PIMENTA, 2006, p. 24).

A autora propõe que se realize uma emancipação do conceito de professor reflexivo, que iria, em um primeiro momento, da reflexão individual à coletiva. Nesse cenário, considera-se de grande importância o papel da teoria, já que os saberes teóricos devem se articular aos saberes práticos, que por sua vez irão proporcionar dados para o repensar do saber teórico. Para a construção da reflexão coletiva, três perspectivas devem ser acionadas conjuntamente: a) a prática reflexiva deve centrar-se no professor; b) a conscientização do professor como agente político; c) a transformação da escola em comunidades de aprendizagem. Assim, o reducionismo de Schön à figura do professor e sua ação em sala de aula seria expandido para o contexto no qual ele está inserido, ainda que as políticas institucionais mais amplas não estejam sobre seu controle.

Em um segundo momento, após a apropriação da reflexão coletiva e a construção da escola como uma comunidade de aprendizagem, torna-se possível partir da reflexão coletiva para a reflexão crítica, que pressupõe o professor reflexivo ou o intelectual crítico. Somente com a apropriação da reflexão crítica é que a escola pode vencer seu maior paradoxo, uma vez que

Por um lado, as finalidades educativas apresentam um discurso de preparar para a vida adulta com capacidade crítica em uma sociedade plural. Por outro, o trabalho docente e a vida da escola se estruturam para negar tais finalidades. [...] A compreensão dos fatores sociais e institucionais que condicionam a prática educativa e a emancipação das formas de dominação que afetam nosso pensamento e nossa ação não são espontâneas e nem se produzem naturalmente. São processos contínuos de descoberta, de transformação das diferenças de nossas práticas cotidianas (PIMENTA, 2006, p. 27-28).

Criar uma cultura reflexiva nas escolas brasileiras é possível, porém é necessário considerar e refletir os apontamentos aqui discutidos para que a as escolas se transformem em comunidades de aprendizagem e propiciem a formação do professor crítico, que analisa sua prática à luz da teoria e fornece instrumentos e meios para que a teoria seja repensada a partir da prática docente, concretizando, assim, o conceito de professor reflexivo.

\section{CONCLUSÃO}

No contexto educacional brasileiro, apesar de as ideias de Schön e a construção do professor reflexivo terem encontrado terreno fértil para sua popularização, as condições de formação da maioria dos docentes, bem como a organização institucional das redes de ensino no país acabam, muitas vezes, por inviabilizar a ação reflexiva, seja ela individual ou coletiva.

Em nossa discussão, refletimos sobre a necessidade de se emancipar o conceito de professor reflexivo afim de não incorrer no reducionismo do professor isolado em sua sala de aula como agente de reflexão individual. Engajar todo o ambiente escolar em práticas reflexivas para criar uma comunidade de aprendizagem coletiva é fundamental para que o professor saia de sua individualidade e torne-se um professor crítico, ainda que o resultado final de sua ação ocorra na singularidade da sua sala de aula.

Entretanto, ao analisar o percurso das reformas curriculares nacionais efetuadas em nosso país, especialmente após a década de 1990, verificamos uma grande falta de diálogo entre os propositores de tais reformas e os professores, que atuarão na aplicação e concretização destas ideias. Cria-se, assim, um ambiente desfavorável à prática reflexiva, uma vez que os professores se 
tornam mero executores de currículos criados em níveis exteriores às escolas e, muitas vezes, com origens em ideias não autóctones sobre o ensino e a concepção de educação.

Em relação ao ensino de geografia, o avanço das teorias críticas na formação dos professores e nos estudos geográficos, não encontra respaldo nas proposições curriculares, uma vez que a simples ausência de diálogo mina quaisquer possibilidades de construção da identidade crítica do professor e sua reflexão frente ao contexto no qual está inserido.

É necessário um repensar das ações pedagógicas visando atingir o seu objetivo maior - a aprendizagem de seus alunos. Para que isso ocorra, para além da postura crítico-reflexiva do professor, são necessárias mudanças estruturais, tanto a nível de políticas públicas para educação, como a nível escolar, com a construção de escolas como comunidades de aprendizagem.

\section{REFERÊNCIAS}

BRASIL, Senado Federal. Lei de Diretrizes e Bases da Educação Nacional: no 9394/96. Brasília: 1996.

, MEC. Orientações curriculares para o Ensino Médio: Ciências Humanas e suas

tecnologias. Brasília: MEC, 2006.

MEC. Parâmetros Curriculares Nacionais: Geografia. 5aa a 8a séries. MEC. Brasília, 2008. FAGUNDES, Tatiana Bezerra. Os conceitos de professor pesquisador e professor reflexivo: perspectivas do trabalho docente. Rev. Bras. Educ., Rio de Janeiro, v. 21, n. 65, p. 281-298, Jun 2016.

GEBRAN, Raimunda Abou. A Geografia no Ensino Fundamental: Trajetória Histórica e Proposições Pedagógicas. Colloquium Humanarum, Presidente Prudente, v. 1, n. 1, p.81-88, jun./dez. 2003.

OLIVEIRA, Cláudia Márcia de Souza. As implicações da implementação do Currículo Oficial do Estado de São Paulo no cotidiano de uma escola. 2012. 177 f. Dissertação (Mestrado) - Curso de Mestrado em Educação, Faculdade de Ciências e Tecnologia - Unesp, Presidente Prudente, 2012. PIMENTA, Selma Garrido. Professor Reflexivo: construindo uma crítica. In: PIMENTA, S. G., GHEDIN, E. (orgs.). Professor reflexivo no Brasil. 4a ed. São Paulo: Cortez, 2006.

PINHEIRO, Antônio Carlos. Trajetória da pesquisa acadêmica sobre o ensino de Geografia no Brasil: 1972-2000. 2003. 277 f. Tese (Doutorado) - Curso de Doutorado em Ciências, Instituto de Geociências, Universidade Estadual de Campinas, Campinas, 2003.

SALVADOR, Angelo Domingos. Métodos e técnicas de pesquisa bibliográfica. Porto Alegre: Sulina Editora, 1991. 